\title{
EUROPIUM SILICATE THIN FILMS FABRICATED BY RF MAGNETRON SPUTTERING AND THERMAL TREATMENT
}

\author{
Young Chul Shin, Eun Hong Kim, and Tae Geun Kim* \\ School of Electrical Engineering, Korea University, Seoul, Korea
}

Received 27 November 2006

\begin{abstract}
We report the fabrication and optical characteristics of europium silicate thin films. Layer structures of $\mathrm{Eu}_{2} \mathrm{O}_{3} / \mathrm{SiO}_{\mathrm{X}} / \mathrm{Si}$ (100) were deposited by an rf-sputtering method and annealed at $1100^{\circ} \mathrm{C}$ by rapid thermal annealing (RTA). Two methods were used for the deposition of $\mathrm{SiO}_{\mathrm{X}}$ layer: One was deposited by sputtering using $\mathrm{SiO}_{2}$ target $(\mathrm{Ar}$ gas at a rate of $50 \mathrm{sccm}$ ) and the other was deposited by reactive sputtering using Si target (Ar gas at a rate of $45 \mathrm{sccm}$, with an $\mathrm{O}_{2}$ gas at a rate of $5 \mathrm{sccm}$ ). Photoluminescence peak at $430 \mathrm{~nm}$ was observed in the sample composed of $\mathrm{SiO}_{\mathrm{X}}$ interlayer sputtered from $\mathrm{SiO}_{2}$ target. In comparison, PL peak at $570 \mathrm{~nm}$ was observed in the other sample, the $\mathrm{SiO}_{\mathrm{X}}$ layer of which was deposited by reactive sputtering from $\mathrm{Si}$ target. The compositional distributions of these samples were analyzed by X-ray photoelectron spectroscopy (XPS).
\end{abstract}

PACS: $74.25 . \mathrm{Gz}, 78.20 .-\mathrm{e}$

Keywords: Sputtering, photoluminescence, photoelectron spectroscopy

\section{INTRODUCTION}

White light-emitting diodes (LEDs) can offer benefits in terms of high luminous efficiency, energy-saving, maintenance and environmental protection. Therefore, they are called the nextgeneration solid-state light, the replacement of conventional incandescent and fluorescent lamps. The technology of white LEDs which is connected with the blue LED coated with a YAG: Ce phosphor, has improved the white LED efficiencies [1 - 2]. However, the brightness and color purity of blue LED-based white LEDs are dependent on the conditions of forwardbias and phosphor coating. An alternative method of making a color conversion white LEDs is that a true white can be achieved using three colors from red, green, and blue phosphors excited by ultraviolet (UV) LEDs, similar to three colors based fluorescent lamp [3]. It is very important to improve the efficiency of the RGB phosphor as well as that of the UV LED chip to fabricate highly efficient white LEDs. Phosphors are usually made of zinc sulfide or yttrium oxides doped with certain transition metals or rare-earth metals to obtain specific colors. The efficiency of the currently applied red phosphor is much lower than that of green phosphor and blue phosphor. Therefore, it should be further improved for the applications such as florescence lamps.

On the other hand, rare-earth silicate compounds have attracted a great deal of interest for their luminescent properties. They have been applied to many practical devices, such as fluorescent lamps, the cathode-ray tube and x-ray recording devices, as well as electroluminescent (EL) devices [4 - 7]. In particular, europium silicate compounds are known as an intense and stable

\footnotetext{
* Corresponding author e-mail: tgkim1@ korea.ac.kr
} 
luminescent material in the visible region [8 - 12]. Several works have been done so far regarding the structure and the electrical/optical/magnetic properties of europium-silicate compounds [9 - 12]. However, the growth of single-phased europium silicate crystals is performed at high temperatures. For example, the bulk $\mathrm{Eu}_{2} \mathrm{SiO}_{4}$ crystals are grown at a temperature of $1800^{\circ} \mathrm{C}$ [9] and $\mathrm{EuSiO}_{3}$ crystals have been obtained at $1400^{\circ} \mathrm{C}$ [10]. In addition, due to difficulties in growing pure crystals, a few studies of the applications of pure europium silicates have been done compared to other europium doped materials, which are known as the intense and stable luminescent materials in the visible region.

In this work, we report the fabrication and optical characteristics of europium silicate thin films. Layer structures of $\mathrm{Eu}_{2} \mathrm{O}_{3} / \mathrm{SiO}_{\mathrm{X}} / \mathrm{Si}$ (100) were deposited by an rf-sputtering method and annealed at $1100^{\circ} \mathrm{C}$ by rapid thermal annealing (RTA). The samples were characterized by using $\mathrm{X}$-ray photoelectron spectroscopy (XPS). Then, photoluminescence (PL) properties of the europium-silicate thin films were investigated, and the results are discussed.

\section{EXPERIMENTS}

Figure 1 shows a schematic of the $\mathrm{Eu}_{2} \mathrm{O}_{3} / \mathrm{SiO}_{\mathrm{X}} / \mathrm{Si}$ structures prepared rf-sputtering method. Two methods were used for the deposition of $\mathrm{SiO}_{\mathrm{X}}$ layer: One is deposited by using rf sputtering method in Ar gas at a rate of $50 \mathrm{sccm}$ with $\mathrm{SiO}_{2}(99.9 \%)$ target and the other is deposited by reactive sputtering using a sputtering atmosphere gas mixture of $\mathrm{Ar}$ and $\mathrm{O}_{2}$ with $\mathrm{Si}$ (99.9\%) target. The volume fraction of $\mathrm{O}_{2}$ was adjusted to $10 \%$ (Ar gas at a rate of $45 \mathrm{sccm}$, with an $\mathrm{O}_{2}$ gas at a rate of $5 \mathrm{sccm})$. Europium-oxide thin films were prepared on p-type $\mathrm{Si}(100)$ substrates and by using an rf sputtering method in $\mathrm{Ar}$ gas with an $\mathrm{Eu}_{2} \mathrm{O}_{3}(99.95 \%)$ target. During the sputtering process, the atmosphere gas pressure was kept at 4.4 mTorr, and the rf power was 70 $\mathrm{W}$ and the substrate was not heated during sputtering. The deposited film thickness was about $0.2 \mu \mathrm{m}$ and $0.2 \mu \mathrm{m}$ for europium oxide and silicon oxide, respectively. After sputtering, the films were annealed in the temperate range of $900 \sim 1100{ }^{\circ} \mathrm{C}$ for $5 \mathrm{~min}$ in a nitrogen ambient by using rapid thermal annealing (RTA).

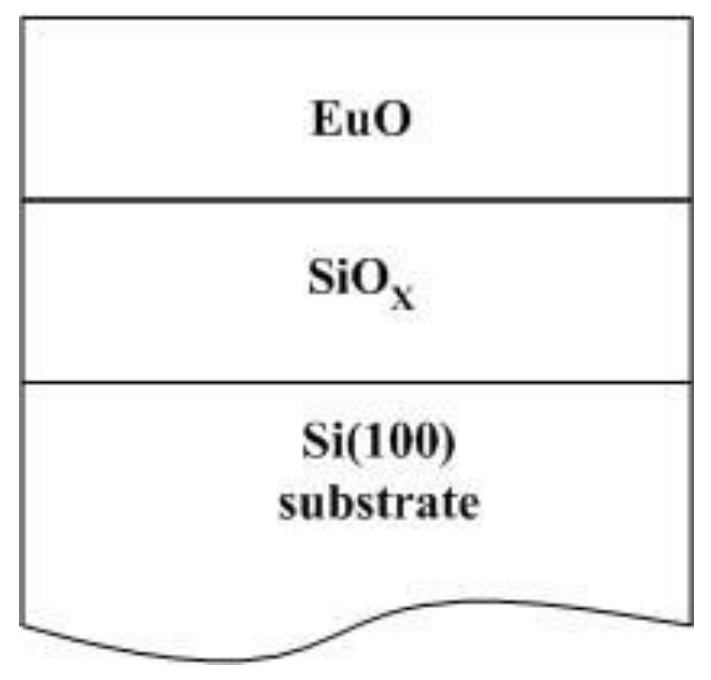

Fig. 1: A basic scheme of the thin film prepared rf-sputtering method

The samples were investigated in order to determine the compositional distribution as a function of depth in the film by XPS ion beam sputtering with argon. This technique is usually used for 148 
removing contaminated surface layers. However, since sputtering physically removes material (i.e., it etches) from the surface, it can also be used for depth profiling. The XPS measurements were carried out in a Perkin-Elmer Model PHI 5800 ESCA system with a monochromatic x-ray source of $\mathrm{Al} \mathrm{K \alpha}(1486.6 \mathrm{eV})$. The spectrometer was operated at a constant pass energy of $187.85 \mathrm{eV}$. An energy step of $0.125 \mathrm{eV}$ was used to acquire the XPS spectra. The PL emission spectra of the samples were obtained using a $325 \mathrm{~nm} \mathrm{He}-\mathrm{Cd}$ laser at room temperature.

\section{RESULTS}

Table 1 describes two representative thin-film samples, labeled ES1 and ES2. These samples were prepared by the rf-sputtering method. The thin films of the samples ES1 and ES2 were prepared on $\mathrm{Si}(100)$ substrates. After sputtering, the films were annealed at the temperature of $1100^{\circ} \mathrm{C}$ for $5 \mathrm{~min}$ in nitrogen ambient by rapid thermal annealing method.

Table 1: Growth conditions for europium silicate thin films used in this experiment

\begin{tabular}{cccccc}
\hline Sample & Substrate & Target for EuO layer & Sputter gas & Target for $\mathrm{SiO}_{\mathrm{x}}$ layer & Sputter gas \\
\hline $\mathrm{ES} 1$ & $\mathrm{Si}(100)$ & $\mathrm{Eu}_{2} \mathrm{O}_{3}$ & $\mathrm{Ar}$ & $\mathrm{Si}$ & $\mathrm{Ar} / \mathrm{O}_{2}$ \\
$\mathrm{ES} 2$ & $\mathrm{Si}(100)$ & $\mathrm{Eu}_{2} \mathrm{O}_{3}$ & $\mathrm{Ar}$ & $\mathrm{SiO}_{2}$ & $\mathrm{Ar}$ \\
\hline
\end{tabular}

The samples have been studied by the XPS to investigate the compositional distribution of the thin film samples. The peaks monitored in these spectra correspond to Si 2p, O 1s, and Eu 3d core levels. Depth profiles are used to determine the elemental composition as a function of depth. A rastered, differentially pumped argon ion gun was used to sputter the surface of the reflective dielectric film. The sputter rate of $\mathrm{SiO}_{2}$ was used to express the thickness of the layers in the europium silicate thin films. The atomic concentrations are deduced from the XPS spectra using Physical Electronics Inc., MULTIPAK program [13] and by taking atomic-sensitivity factors into consideration. XPS measurements were done in a system separate from the growth chamber and the samples were exposed to the ambient gases during the transfer process. Due to this, these films had a surface layer of carbonaceous compounds. Figure 2 shows the XPS depth profiles of the thin films (a) as-deposited and (b) annealed at $1100^{\circ} \mathrm{C}$ for $5 \mathrm{~min}$ for the sample ES1. The depth profile of the as-deposited thin film shows clearly the different oxide layers of the europium oxide and the silicon oxide. The $1100^{\circ} \mathrm{C}$-annealed thin films of the sample ES1 are composed of $\mathrm{Eu}, \mathrm{O}$ and $\mathrm{Si}$. The variations of the atomic concentration show that some $\mathrm{Si}$ atoms are diffused into the europium oxide thin film out of the silicon oxide while Eu atoms are diffused into the silicon oxide, leading to a composite film of Eu, $\mathrm{O}$ and Si. Figure 3 shows the XPS depth profiles of the thin films (a) as-deposited and (b) annealed at $1100^{\circ} \mathrm{C}$ for $5 \mathrm{~min}$ for the sample ES2. The depth profile of the as-deposited thin film shows clearly the different oxide layers similar to that of as-deposited thin film of the sample ES2. It is observed that the silicon concentration in the europium silicate layer of the sample ES1 annealed at $1100^{\circ} \mathrm{C}$ is greater than that in the layer of the sample ES2 annealed at $1100^{\circ} \mathrm{C}$. On the other hand, the europium concentration in the layer of the sample ES1 annealed at $1100^{\circ} \mathrm{C}$ is less than that in the layer of the sample ES2 annealed at $1100^{\circ} \mathrm{C}$. This indicates that a composite film of $\mathrm{Eu}, \mathrm{O}$ and $\mathrm{Si}$ is easy to form in the thin film of the sample ES1 rather than that of the sample ES2. In other words, the reaction between the europium oxide and the silicon oxide was suppressed in the sample ES2.

Figure 4 shows the PL peak wavelengths from the thin films of the samples ES1 and ES2 after thermal treatment at $900 \sim 1100^{\circ} \mathrm{C}$. In case of the sample ES2, the PL peak wavelength does not change as the annealing temperature changes from $900^{\circ} \mathrm{C}$ to $1100^{\circ} \mathrm{C}$. The PL signal is centered 
at $430 \mathrm{~nm}$ in the sample ES2 after thermal treatment. By contrast, the red-shift of the PL peak occurred when the sample ES1 was annealed above $1000^{\circ} \mathrm{C}$. A very strong luminescence in the visible region was observed from the thin film in the sample ES1 annealed at $1100^{\circ} \mathrm{C}$, with the maximum intensity at $570 \mathrm{~nm}$ and a full width at maximum of $190 \mathrm{~nm}$. This broad spectrum is thought to originate from the $4 \mathrm{f}^{6} 5 \mathrm{~d}-4 \mathrm{f}^{7}$ transition of divalent europium ions $\mathrm{Eu}^{2+}$ at different sites [12]. The intense and broad luminescent properties of the europium-silicate thin films are expected to have wide applications in areas of passive optical components, like thin film phosphors, and active components, like electroluminescence devices.
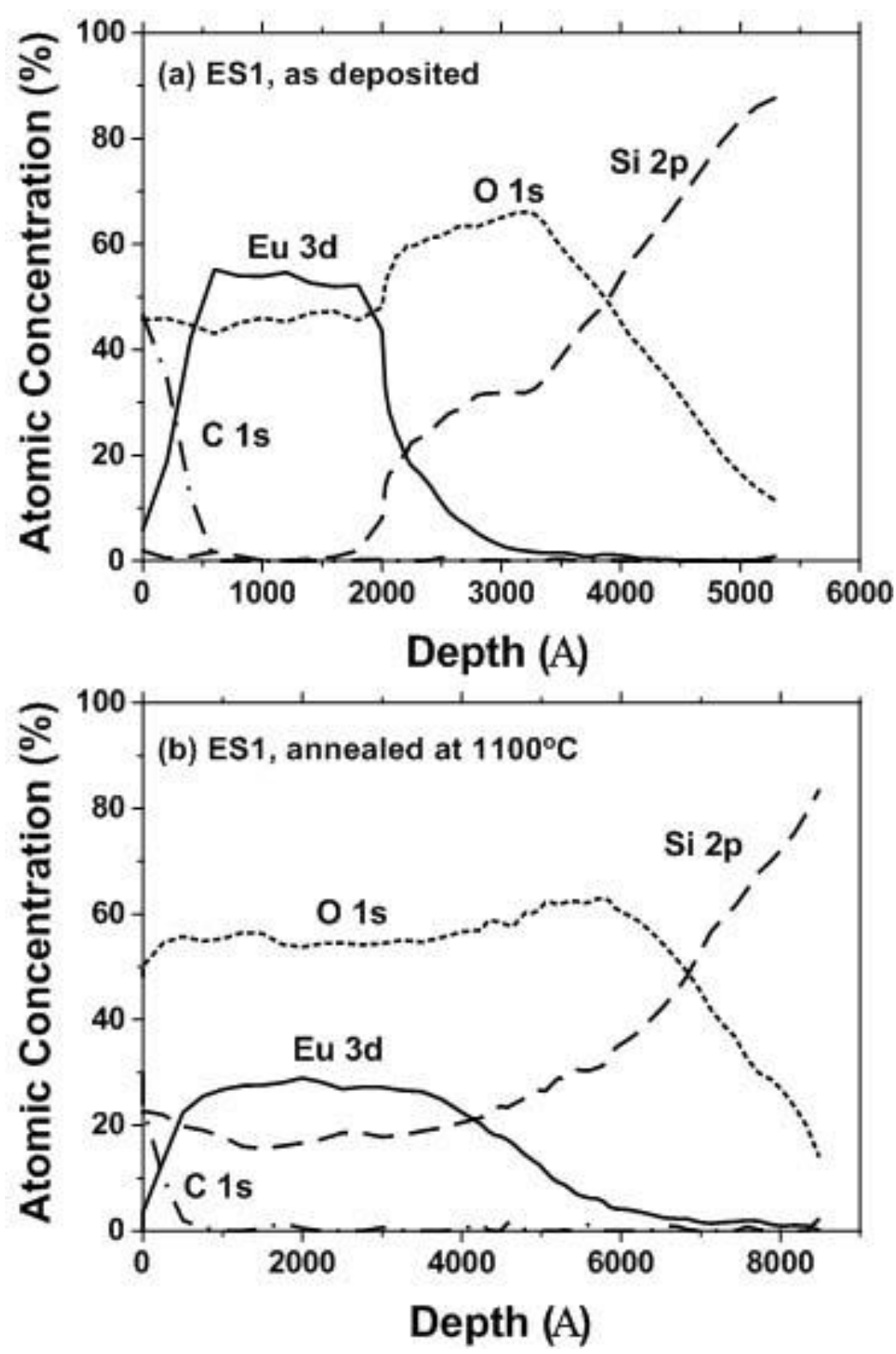

Fig. 2: XPS depth profiles of the atomic concentrations of silicon, oxygen and europium for the samples (a) as-deposited and (b) annealed at $1100^{\circ} \mathrm{C}$ for the sample ESI 

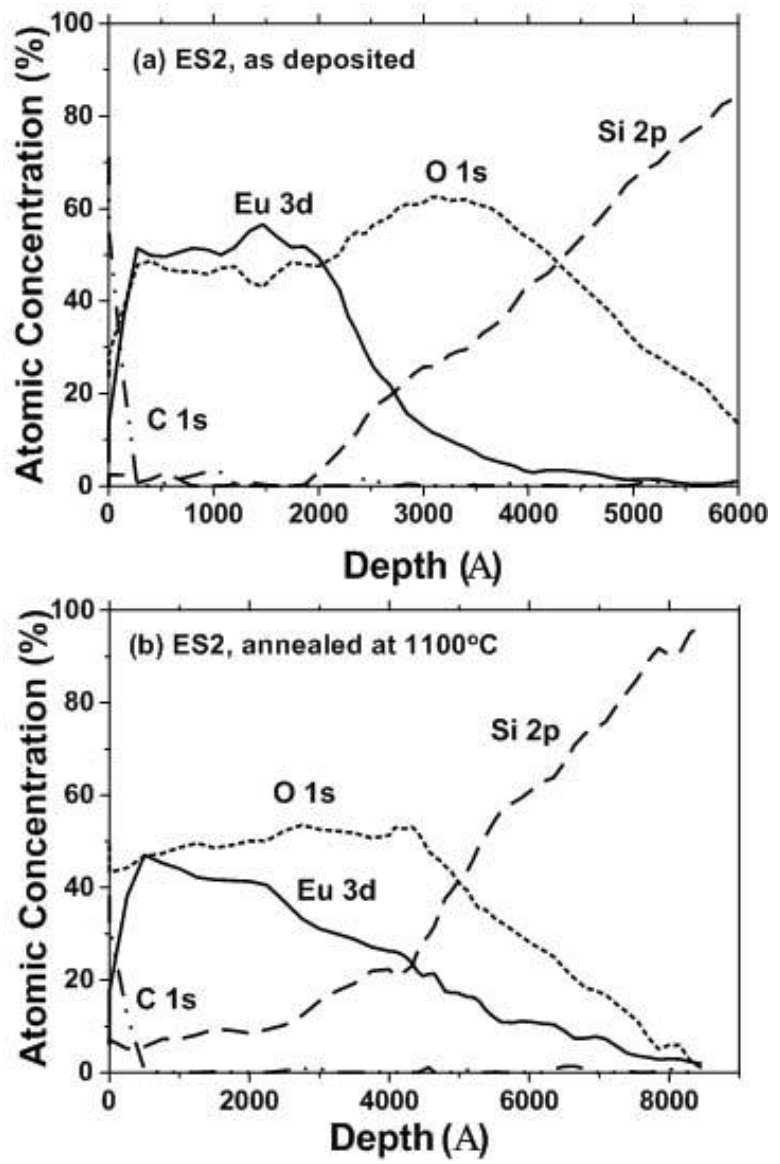

Fig. 3: XPS depth profiles of the atomic concentrations of silicon, oxygen and europium for the samples (a) as-deposited and (b) annealed at $1100^{\circ} \mathrm{C}$ for the sample ES2

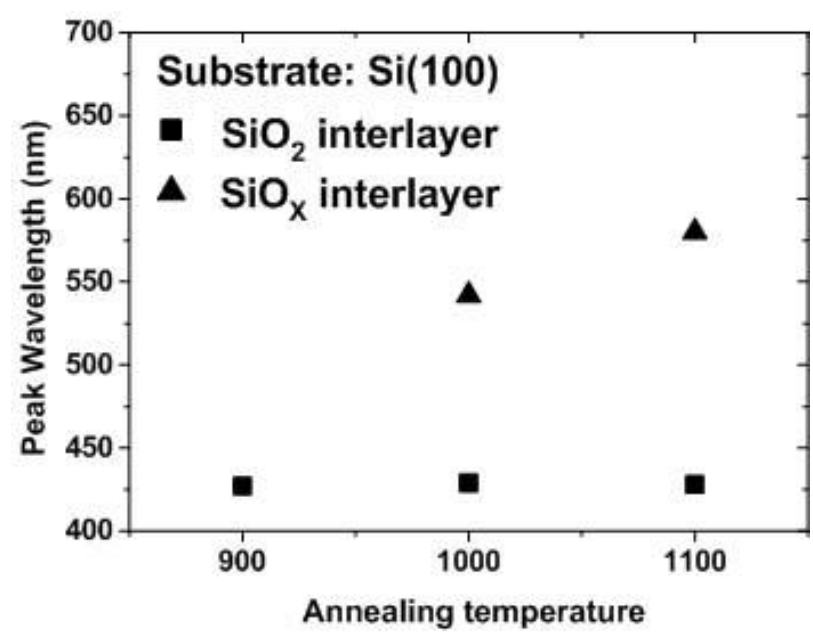

Fig. 4: Peak wavelengths of photoluminescence with an excitation wavelength of $325 \mathrm{~nm}$ (HeCd laser) from the samples (a) ES1 and (b) ES2 after thermal treatment at 900 $1100^{\circ} \mathrm{C}$ 


\section{CONCLUSION}

We report the effect of $\mathrm{SiO}_{\mathrm{X}}$ Intermediate Layers on PL properties of europium silicate thin films. Layer structures of $\mathrm{Eu}_{2} \mathrm{O}_{3} / \mathrm{SiO}_{X} / \mathrm{Si}(100)$ were deposited by an rf-sputtering method and annealed at $1100^{\circ} \mathrm{C}$ by RTA. Two methods were used for the deposition of $\mathrm{SiO}_{\mathrm{X}}$ layer: One was deposited by sputtering using $\mathrm{SiO}_{2}$ target (Ar gas at a rate of $50 \mathrm{sccm}$ ) and the other was deposited by reactive sputtering using $\mathrm{Si}$ target (Ar gas at a rate of $45 \mathrm{sccm}$, with an $\mathrm{O}_{2}$ gas at a rate of $5 \mathrm{sccm}$ ). Photoluminescence peak at $430 \mathrm{~nm}$ was observed in the sample composed of $\mathrm{SiO}_{\mathrm{X}}$ interlayer sputtered from $\mathrm{SiO}_{2}$ target. In comparison, the intense and broad PL peak at 570 $\mathrm{nm}$ was observed in the other sample, the $\mathrm{SiO}_{\mathrm{X}}$ layer of which was deposited by reactive sputtering from Si target.

\section{ACKNOWLEDGEMENT}

This work was supported by MOST/KOSEF through the Quantum Photonic Science Research Center.

\section{REFERENCES}

1. Tamura, T., Setomoto, T., and Taguchi, T. (2000), J. Luminescence, vol. 87-89, p. 1180.

2. Uchida, Y., Setomoto, T., Taguchi, T., Nakagawa, Y., and Miyazaki, K. (2000), In Display Technologies III, vol. 4079, p. 120, The International Society for Optical Engineering, Bellingham, WA.

3. Mueller-Mach, R., Mueller, G.O., Krames, M.R., and Trottier, T. (2002), IEEE J. Sel. Topics Quantum Elecrton., vol. 8, p. 339.

4. Shafer, M.W., McGuire, T.R., and Suits, J.C. (1963), Phys. Rev. Lett., vol. 11, p. 251.

5. Kaldis, E., Streit, P., and Wachter, P. (1971), J. Phys. Chem. Solids, vol. 32, p. 159.

6. Machida, K., Adachi, G., Shiokawa, J., Shimada, M., Koizumi, M., Suito, K., and Onodera, A. (1982), Inorg. Chem., vol. 21, p. 1512.

7. Qi, J., Matsumoto, T., Tanaka, M., and Masumoto, Y. (1999), Appl. Phys. Lett., vol. 74, p. 3203.

8. Choi, W., Lee, H., Kim, E., Kim, Y., Park, C., Kim, H., and Lee, J. (1999), Appl. Phys. Lett., vol. 75, p. 2389.

9. Yi, S. (2004), J. Korean Phys. Soc., vol. 45, p. 1625.

10. Potdevin, A., Chadeyron, G., Boyer, D., Caillier, B., and Mahiou, R. (2005), J. Phys. D: Appl. Phy., vol. 38, p. 3251.

11. Park, J., Back, N., Hong, K., Kim, C., Yoo, D., Kwak, M., Han, J., Hong, S., Moon, B., Seo, H., and Choi, B. (2005), J. Korean Phys. Soc., vol. 47, p. 368.

12. Bae, J., Shim, K., Moon, B., Kim, S., Jeong, J., Yi, S., and Kim, J. (2005), J. Korean Phys. Soc., vol. 46, p. 1193.

13. Physical Electronics, Inc., 6509 Flying Cloud Drive, Eden Prairie, MN 55344. 